Philippe Letocart Christine Brasse Arnaud Delahaye Sébastien Ena

\section{Emphysematous gastritis: a rare cause of septic shock}

Received: 26 July 2013

Accepted: 6 September 2013

Published online: 1 October 2013

(C) Springer-Verlag Berlin Heidelberg and ESICM 2013

P. Letocart $(\bowtie) \cdot$ C. Brasse - A. Delahaye - S. Ena

Centre Hospitalier de Rodez, Avenue de l'Hôpital, Rodez, France e-mail: letocartphilippe@yahoo.fr

A 84-year-old man was admitted to our ward for septic shock. An abdominal computed tomography (CT) scan revealed unexpected emphysematous gastritis with air in the portal venous system without any signs of pneumoperitoneum or peritoneal effusion. The upper endoscopy revealed only gastritis in the fundus. A medical treatment was decided upon in which the surgeon used fluid loading, norepinephrine and probabilistic antibiotic. A control CT scan on day 4 did not show any air except in a small portion of the portal system. No microbiologic documentation could be confirmed. Complete cure was fast,

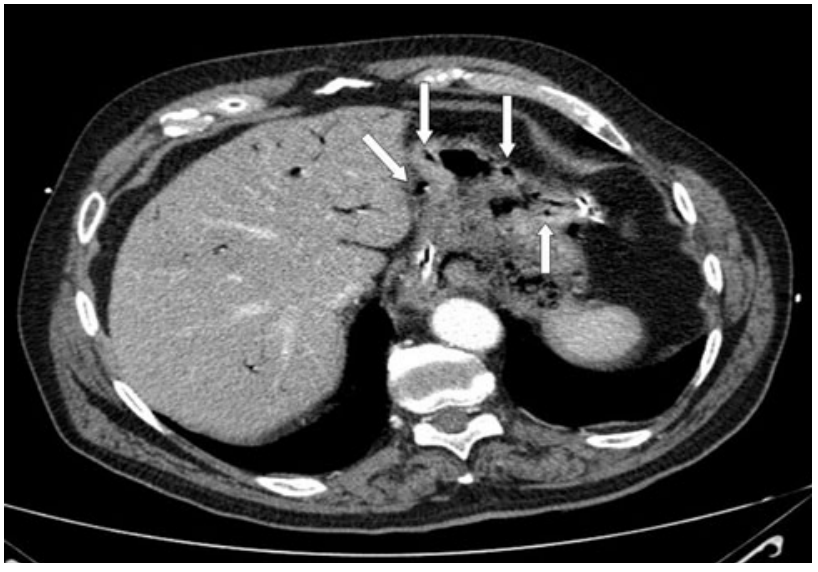

Fig. 1 Transversal view of an abdominal computed tomography scan showing air in the portal venous system and in the gastric wall (white arrows)

enabling the patient to be quickly transferred out of the intensive care unit and discharged from the hospital (Fig. 1).

Conflicts of interest None. 